\title{
Mycobacterium shigaense Causes Lymph Node and Cutaneous Lesions as Immune Reconstitution Syndrome in an AIDS Patient: The Third Case Report of a Novel Strain Non-tuberculous Mycobacterium
}

\author{
Yusuke Koizumi $^{1,2}$, Kaoru Shimizu ${ }^{3}$, Masayo Shigeta ${ }^{3}$, Hitoshi Minamiguchi ${ }^{2}$, \\ Keiko Hodohara ${ }^{2}$, Akira Andoh ${ }^{2}$, Toshihide Tanaka ${ }^{4}$, Kinuyo Chikamatsu ${ }^{5}$, \\ Satoshi Mitarai ${ }^{5}$ and Hiroshige Mikamo ${ }^{1}$
}

\begin{abstract}
A 40-year-old man complaining of progressive body weight loss was diagnosed to have acquired immunodeficiency syndrome. Within 2 weeks after the initiation of combination antiretroviral therapy, he developed fever, massive cervical lymphadenopathy and a protruding subcutaneous abscess. A lymph node biopsy and abscess drainage revealed non-caseous granuloma and mycobacterium. The mycobacterium belonged to Runyon II group, but it showed no matches to any previously reported species. According to sequence analyses, the strain was identified as Mycobacterium shigaense. After six months of antimycobacterial treatment, the lesions were all successfully cured. This is the third case report of the novel mycobacterium, M. shigaense, presenting in associatioin with immune reconstitution syndrome.
\end{abstract}

Key words: acquired immunodeficiency syndrome (AIDS), non-tuberculous mycobacteria (NTM), immune reconstitution syndrome (IRS), lymphadenitis, Mycobacterium shigaense

(Intern Med 55: 3375-3381, 2016)

(DOI: 10.2169/internalmedicine.55.6996)

\section{Introduction}

Non-tuberculous mycobacteria (NTM) are ubiquitous bacteria found in the soil, water, plant or animals. While person-to-person transmission is rare, they sometimes cause life threatening disease in compromised hosts (1). Especially in acquired immunodeficiency syndrome (AIDS) patients, Mycobacterium avium complex (MAC) often causes disseminated infection (2). The advent of combination antiretroviral therapy (cART) has greatly improved the prognosis of AIDS patients, but at the same time, unfavorable excessive inflammation, i.e., immune reconstitution syndrome (IRS) has emerged as a result of strong and rapid immune restora- tion (3).

MAC is one of the most common etiologic pathogen for IRS, but it is also well known that NTM other than MAC, for example, M. genavense, M. fortuitum, M. xenopi or $M$. kansasii are often seen in AIDS patients $(1,4)$. Besides, in addition to conventional culture methods, recent progress in molecular biology has offered new insight into many other species of NTM (5-8). In AIDS patients, too, cases with newly identified mycobacteria such as $M$. triplex (9), M. lentiflavum (10), or M. parascrofulatum (11) have been reported.

Mycobacterium shigaense is a novel NTM strain (12). There have only been two case reports so far, and little is known about this organism. We herein report the third

\footnotetext{
${ }^{1}$ Department of Clinical Infectious Diseases, Aichi Medical University Hospital, Japan, ${ }^{2}$ Department of Gastroenterology and Hematology, Shiga University of Medical Science, Japan, ${ }^{3}$ Department of Laboratory Medicine, Shiga University of Medical Science, Japan, ${ }^{4}$ Department of Dermatology, Shiga University of Medical Science, Japan and ${ }^{5}$ Department of Mycobacterium Reference and Research, Research Institute of Tuberculosis, Japan Anti-Tuberculosis Association, Japan

Received for publication December 17, 2015; Accepted for publication February 26, 2016

Correspondence to Dr. Yusuke Koizumi, ykoizumi@aichi-med-u.ac.jp
} 
Table 1. Laboratory Findings at First Visit.

\begin{tabular}{|c|c|c|c|c|c|}
\hline WBC & $2,500 / \mu \mathrm{L}$ & TP & $8.3 \mathrm{~g} / \mathrm{dL}$ & $\mathrm{Fe}$ & $77 \mathrm{mg} / \mathrm{dL}$ \\
\hline Neut & $65 \%$ & ALB & $4.5 \mathrm{~g} / \mathrm{dL}$ & UIBC & $180 \mathrm{mg} / \mathrm{dL}$ \\
\hline Eosin & $9.6 \%$ & AST & $27 \mathrm{U} / \mathrm{L}$ & $\operatorname{IgG}$ & $1,761 \mathrm{mg} / \mathrm{dL}$ \\
\hline Baso & $0 \%$ & ALT & $23 \mathrm{U} / \mathrm{L}$ & IgM & $76 \mathrm{mg} / \mathrm{dL}$ \\
\hline Lymph & $20.6 \%$ & $\mathrm{LDH}$ & $304 \mathrm{U} / \mathrm{L}$ & $\operatorname{IgA}$ & $385 \mathrm{mg} / \mathrm{dL}$ \\
\hline Mono & $4.8 \%$ & ALP & $476 \mathrm{U} / \mathrm{L}$ & CRP & $0.32 \mathrm{mg} / \mathrm{dL}$ \\
\hline $\mathrm{RBC}$ & $448 \times 10^{6} / \mu \mathrm{L}$ & $\gamma$-GTP & $35 \mathrm{U} / \mathrm{L}$ & Ferritin & $531.4 \mathrm{ng} / \mathrm{mL}$ \\
\hline $\mathrm{Hb}$ & $13.3 \mathrm{~g} / \mathrm{dL}$ & $\mathrm{CHE}$ & $405 \mathrm{U} / \mathrm{L}$ & sIL2-Rec & $600 \mathrm{U} / \mathrm{mL}$ \\
\hline $\mathrm{Ht}$ & $38.6 \%$ & T-BIL & $0.71 \mathrm{mg} / \mathrm{dL}$ & & \\
\hline PLT & $12.8 \times 10^{4} / \mu \mathrm{L}$ & D-BIL & $0.16 \mathrm{mg} / \mathrm{dL}$ & \multirow{2}{*}{\multicolumn{2}{|c|}{ HIV-1RNA $1,400,000$ copies $/ \mathrm{mL}$}} \\
\hline & & NA & $142 \mathrm{mEq} / \mathrm{L}$ & & \\
\hline CD3 & $54 \%$ & $\mathrm{CL}$ & $107 \mathrm{mEq} / \mathrm{L}$ & $\beta$-D-glucan & $<5.0 \mathrm{pg} / \mathrm{mL}$ \\
\hline CD19 & $24 \%$ & $\mathrm{~K}$ & $4.2 \mathrm{mEq} / \mathrm{L}$ & & \\
\hline CD4 & $2 \%$ & UN & $10.1 \mathrm{mg} / \mathrm{dL}$ & CMV antigenemia & $(-)$ \\
\hline CD8 & $44 \%$ & CRE & $0.7 \mathrm{mg} / \mathrm{dL}$ & \multirow{5}{*}{$\begin{array}{l}\text { HBs antigen } \\
\text { HCV antibody } \\
\text { TPLA } \\
\text { RPR }\end{array}$} & $(-)$ \\
\hline CD4 count & $10 / \mu \mathrm{L}$ & UA & $5.7 \mathrm{mg} / \mathrm{dL}$ & & $(-)$ \\
\hline & & $\mathrm{T}-\mathrm{CHO}$ & $198 \mathrm{mg} / \mathrm{dL}$ & & $(-)$ \\
\hline & & TG & $191 \mathrm{mg} / \mathrm{dL}$ & & $(-)$ \\
\hline & & AMY & $92 \mathrm{U} / \mathrm{L}$ & & \\
\hline & & CPK & $45 \mathrm{mg} / \mathrm{dL}$ & & \\
\hline
\end{tabular}

CMV: cytomegalovirus, RPR: rapid plasma reagin test, sIL2-Rec: soluble interleukin-2 receptor, TPLA: Treponema pallidum latex agglutination test

known case of $M$. shigaense, causing IRS soon after the initiation of cART.

\section{Case Report}

A 40-year-old man who had been treated for recurrent oral candidiasis came to our hospital because of general malaise and progressive body weight loss, losing $10 \mathrm{~kg}$ in a half year. He was bisexual, having no habit of intravenous drug use. While he had no history of any sexually transmitted diseases, he had experienced herpes zoster 5 years before, but he had never taken any human immunodeficiency virus (HIV) antibody tests.

At presentation, he had low grade fever, gum bleeding and tinglingness in the posterior cervical region. He complained of no particular respiratory and gastrointestinal symptoms. Physical examination revealed oral candidiasis, gingivitis and slight lymphadenopathy involving the cervical, submandibular, left postauricular and inguinal nodes (measuring 4-5 $\mathrm{mm}$ in diameter, without tenderness). The liver and spleen were not palpable. Folliculitis was seen on the trunk and extremities. An HIV screening test was positive and a Western blot test was done, and it proved to be positive. Blood examination results were as follows (Table 1); HIV-RNA 1,400,000 copies/mL, CD4 count 10/ $\mathrm{LL}$, slight pancytopenia, and hypergloburinemia were seen. The serum alkaline phosphatase (ALP) level and lactate dehydrogenase (LDH) level were slightly elevated. With an extremely low CD4 count and wasting syndrome, he was diagnosed as having AIDS. Therefore, a thorough examination regarding opportunistic infections and sexually transmitted diseases was done. Plasma (1->3) $\beta$-D-glucan, cytomegalovirus antigenemia, HBs-antigen, hepatitis $\mathrm{C}$ virus $(\mathrm{HCV})$ antibody, and Treponema pallidum latex agglutination test, and rapid plasma reagin test were negative. Blood, fecal, sputum, and urine cultures were done, but no particular microbes includ- ing bacteria, mycobacteria, fungi, and protozoa were detected. A computed tomography (CT) scan showed slight splenomegaly and lymph node swelling in the neck areas. Lymphadenopathy was not detected in the thorax or abdomen. No lung lesions were found in a CT scan. Brain MRI, esophagogastroduodenoscopy and total colonoscopy showed no abnormalities. Pneumocystis pneumonia (PCP) was not suspected, and sulfamethoxazole $800 \mathrm{mg} /$ trimethoprim 160 $\mathrm{mg}$ was administered as PCP prophylaxis. Oral azithromycin $1,200 \mathrm{mg}$ weekly was also started as prophylaxis for the MAC infection. At that time, no respiratory symptoms were observed, and mycobacterium was not detected in a smear. However, after four weeks of incubation mycobacterium was detected in a sputum culture, but polymerase chain reaction (PCR) tests for M. tuberculosis and MAC were negative.

After the completion of fluconazole therapy for oral candidiasis, cART was started with abacavir, lamivudine and darunavir/ritonavir. On day 11 (of cART), fever, tender submental lymph node swelling and trismus developed. On day 18 , his temperature rose to $40^{\circ} \mathrm{C}$ and cervical lymph node (LN) swelling became more conspicuous with severe tenderness (Fig. 1). The serum ALP level was 618 U/L and MACIRS was suspected. On day 28, we performed a biopsy of the submental lymph node. At this time, the CD4 count was $94 / \mu \mathrm{L}$ and the serum HIV-RNA level had declined to 1,700 copies/mL.

The sampled lymph node had swollen to $2 \mathrm{~cm}$ in diameter and the surface of section was gray-white with focal yellowish area. Histologically, non-caseous granuloma was seen (Fig. 2a), and relatively thin bacilli were detected in ZiehlNeelsen staining (Fig. 2b). Mycobacterium was isolated after 8.8 days in supplemented Middlebrook $7 \mathrm{H} 9$ broth liquid culture (BacT/ALERT ${ }^{\circledR}$ MP for mycobacterium, Biomerieux, USA) and after 11 days in 7H11 agar culture. In 2\% Ogawa egg slant medium (Kyokuto Pharmaceutical Industrial, Tokyo, Japan), it was scotochromogenic with an intense yellow 

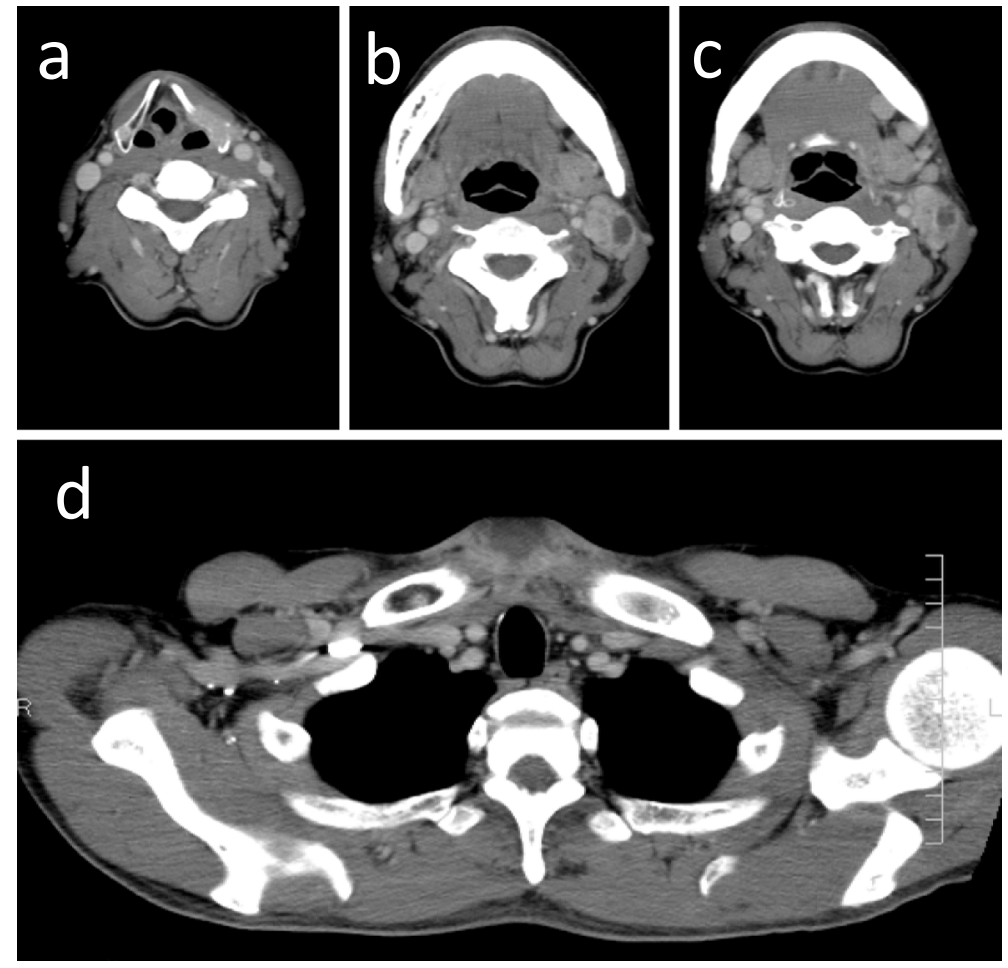

Figure 1. Neck CT findings at day 28 of cART. a: Osteolytic invasion into the thyroid cartilage can be seen. b, c: Multiple cervical lymphadenopathy contains abscess lesions. d: Subcutaneous abscess can be seen in front of the manubrium sterni.

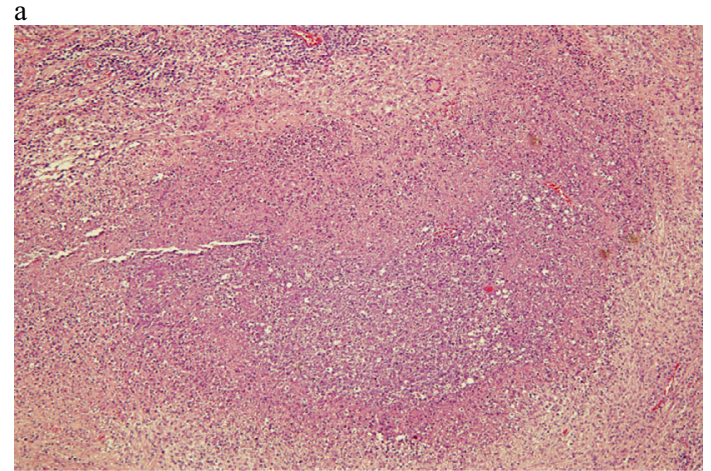

$\mathrm{b}$

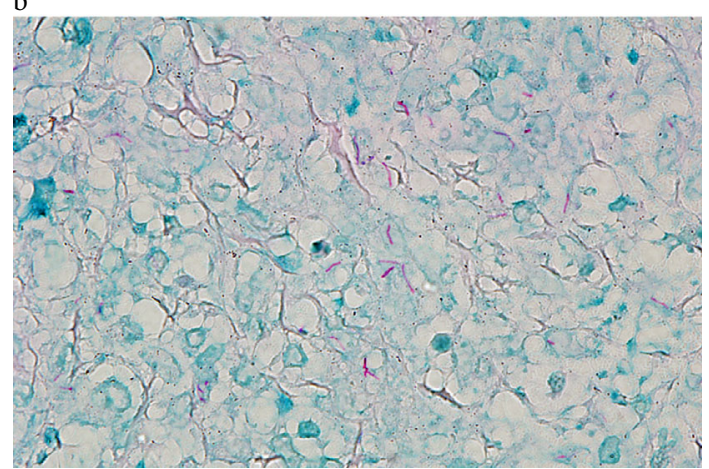

Figure 2. Histological findings after a lymph node biopsy. a: Granuloma is seen (Hematoxylin and Eosin staining, 40x). b: Thin acid fast bacilli are detected (Ziehl-Neelsen stain, 1,000x).

color in both light and dark conditions (Fig. 3). Therefore, the strain was thought to belong to the Runyon II group.

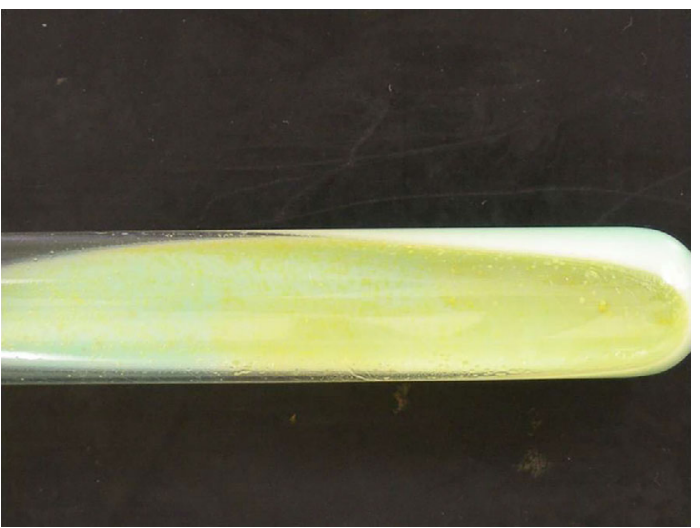

Figure 3. Scotochromogenic colonies of the Mycobacterium shigaense sub-cultured on $2 \%$ Ogawa egg slant medium.

DNA-DNA hybridization (DDH Mycobacteria ${ }^{\circledR}$ Kyokuto Pharmaceutical Industrial) was done, but there were no matches with any of the 18 mycobacterial species.

To identify this isolate, sequence analyses were performed, targeting fragments of the $16 \mathrm{~S}$ ribosomal RNA (16S rRNA, $269 \mathrm{bp}$ ), RNA polymerase B (rpoB, $315 \mathrm{bp}$ ), and heat shock protein 65 ( $h s p 65,401$ bp) genes. In a $16 \mathrm{~S}$ rRNA sequence, although this isolate best matched with $M$. simiae with $99.7 \%$ homology, it also matched several reference strains with more than $98.5 \%$ homology ( $M$. lentiflavum, M. triplex, M. genavense, M. intermedium, M. scrofulaceum, M. kansasii and M. gastri). The sequence analysis showed a high homology rate with Mycobacterium sp. UN- 
Table 2. Antibiotic Susceptibility Tests.

\begin{tabular}{lccc}
\hline & & $\begin{array}{c}\text { Minimal Inhibitory } \\
\text { Concentration } \\
(\mu \mathrm{g} / \mathrm{mL})\end{array}$ \\
\hline $\begin{array}{l}\text { clarithromycin } \\
\text { rifampicin }\end{array}$ & $(\mathrm{CAM})$ & 16 \\
rifabutin & $(\mathrm{RFP})$ & 2 \\
ethanbutol & $(\mathrm{RB})$ & 0.25 \\
isoniazid & $(\mathrm{EB})$ & 4 \\
kanamycin & $(\mathrm{KM})$ & 16 \\
amikacin & $(\mathrm{AMK})$ & 64 \\
streptomycin & $(\mathrm{SM})$ & $>16$ \\
ciprofloxacin & $(\mathrm{CPFX})$ & $>32$ \\
levofloxacin & $(\mathrm{LVFX})$ & $>32$ \\
\hline
\end{tabular}

152, (GeneBank accession no. AB547401) reported as $M$. shigaense; $100 \%$ in $16 \mathrm{~S}$ rRNA, $100 \%$ in rpoB, and $94 \%$ in hsp65. This strain was thus identified to be $M$. shigaense. Later the strain was proven to grow at $25^{\circ} \mathrm{C}, 30^{\circ} \mathrm{C}$ and $37^{\circ} \mathrm{C}$, but not at $42^{\circ} \mathrm{C}$. A niacin test was negative. Table 2 shows the results of antimicrobial susceptibility tests (BrothMIC NTM ${ }^{\circledR}$; Kyokuto Pharmaceutical Industrial). Clarithromycin, ethanbutol and rifabutin seemed to be moderately susceptible, while the others were not susceptible.

An antimycobacterial regimen was started on day 25 of cART. The regimen contained rifabutin (RBT) $150 \mathrm{mg}$, ethanbutol (EB) $750 \mathrm{mg}$, and clarithromycin (CAM) 800 $\mathrm{mg}$. Isoniazid (INH) $300 \mathrm{mg}$ was also added until the subspecies was identified.

Soon after initiation of the regimens, the fever subsided, but lymph node enlargement continued. A subcutaneous abscess with a protruding erythematous lesion appeared on the sternum and grew to $5 \mathrm{~cm}$ in diameter within a week (Fig. 4). Drainage was performed, and again, mycobacterium was found in Ziehl-Neelsen stain, and it was later identified to be $M$. shigaense. Thus, the final diagnosis was immune reconstitution syndrome caused by the novel mycobacterium, M. shigaense. Though we could find mycobacterium in the biopsy or drainage specimens, it took over 4 months to correctly identify this strain. Meanwhile, INH was continued.

The serum ALP level normalized at 12 weeks, HIV-RNA turned to negative at 16 weeks, and the CD4 count recovered to over $100 / \mu \mathrm{L}$ at 27 weeks after the initiation of cART (Fig. 5). Blood, urine and stool cultures for Mycobacterial were repeatedly done, but those were all negative. The skin lesions and lymphadenopathy all gradually improved, and the antimycobacterial regimen was stopped after 6 months. Since then, the patient has been followed up without any recurrence of NTM disease for more than a year.

\section{Discussion}

Mycobacterium shigaense is a novel NTM strain firstly reported by Nakanaga et.al in 2011. Its nucleotide sequence resembles that of $M$. simiae, but it can be distinguished by the temperature it grows (namely, not at $42^{\circ} \mathrm{C}$, while $M$. simiae does grow at $42^{\circ} \mathrm{C}$ ), the presence of colony pigmen-

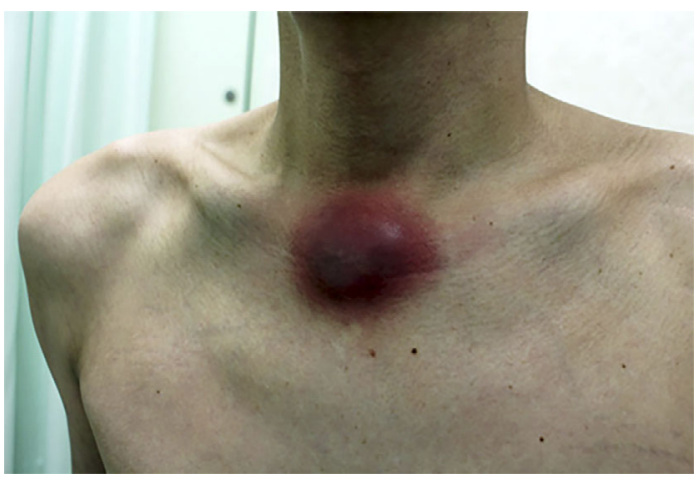

Figure 4. Cutaneous lesions at day 31 of cART.

tation in the dark (while M. simiae is not pigmented in the dark) and negativity for the niacin test (12). There has been two case reports of M. shigaense so far (Table 3) $(12,13)$. The first case was a severely immunocompromized male with Hodgkin lymphoma under chemotherapy. Cutaneous nodules on the back were the main lesions, and CAM and INH were administered for 12 months. The skin lesions often became exacerbated and he finally died due to other opportunistic infections (12). The second case was an immunocompetent female who had papules, nodules and purulent lesions in the face. They were simple chronic skin lesions and were successfully treated with 6 months' medication with CAM and moxifloxacin (13). Both of the cases showed solely cutaneous lesions, but in our case, lymphadenopathy was prominent. Probably the underlying immunodeficiency due to AIDS might explain the reason for the differences in location and the clinical course.

The clinical picture of this case resembles that of disseminated MAC infection in AIDS patients $(14,15)$. Nowadays, it is well known that non-tuberculous mycobacteria other than MAC cause dissemination and IRS $(11,16,17)$. The major risk factors of NTM-IRS development are a low CD4 count or high plasma HIV-RNA at cART initiation (18) and rapid decline in HIV-RNA after cART (19). Our case exactly matches both of these clinical pictures and risk factors of NTM-IRS. First, the main lesions were in the lymph nodes. Second, all the blood culture samples repeatedly taken before and after cART administration were negative for mycobacteria. And third, the onset of IRS occurred at around 2 weeks after cART initiation, with a much higher CD4 count and a dramatically decreased plasma HIV-RNA level in comparison to the values at initial presentation.

It is interesting to note, however, that unlike MAC cases, the three M. shigaense cases including ours demonstrated no lung lesions throughout the whole clinical course. Besides, the mycobacterium was not the cause of death in the first case and the latter two cases were cured with treatment. This is somewhat different from other NTM. Unlike disseminated MAC infection which often requires a longer duration of antimycobacterial treatment, our case did not experience either any recurrence or a refractory course even after the cessation of antimycobacterial regimens. This might be attributed to either the nature of this organism, the early ad- 


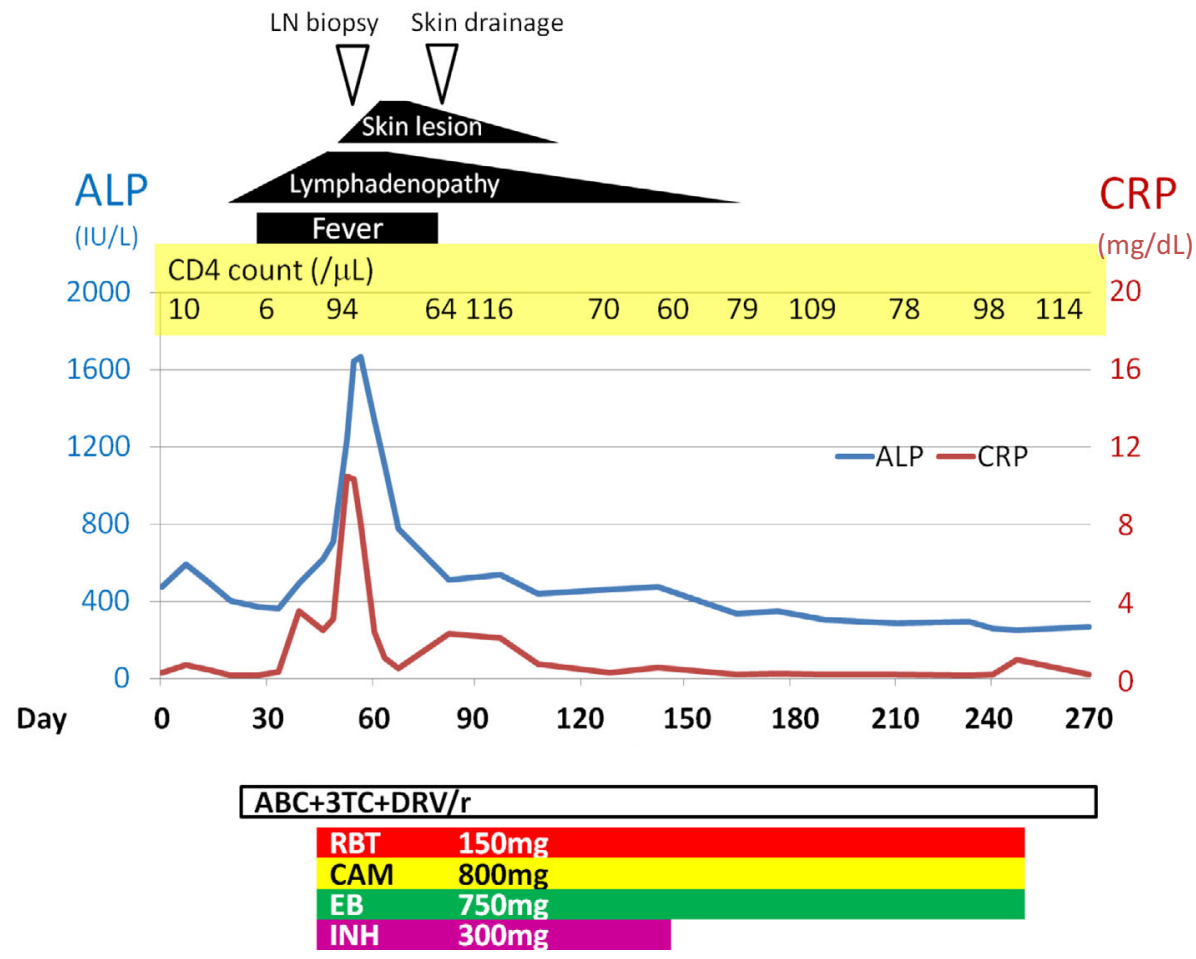

Figure 5. Clinical course. ABC: abacavir, ALP: alkaline phosphatase, CAM: clarithromycin, CRP: C-reactive protein, DRV/r: darunavir/ritonavir, EB: ethanbutol, INH: isoniazid, 3TC: lamivudine, RBT: rifabutin

Table 3. Three Cases of M. shigaense Infection Reported So Far.

\begin{tabular}{|c|c|c|c|}
\hline & case 1 & case 2 & case 3 (present case) \\
\hline Location & Shiga, Japan & Jiangsu, China & Shiga, Japan \\
\hline Age/Sex & $55 / \mathrm{M}$ & $56 / \mathrm{F}$ & $40 / \mathrm{M}$ \\
\hline Comorbidities & $\begin{array}{l}\text { Hodgkin lymphoma } \\
\text { (chemotherapy) } \\
\text { erythroderma } \\
\text { (prednisone) }\end{array}$ & none & AIDS \\
\hline Lesions & skin (back) & skin (cheek) & $\begin{array}{l}\text { cervical lymph nodes } \\
\text { skin (breast) }\end{array}$ \\
\hline $\begin{array}{l}\text { Susceptible } \\
\text { antibiotics }\end{array}$ & $\begin{array}{l}\text { RFP, RBT, CAM, EB, } \\
\text { quinolones, } \\
\text { aminoglycosides }\end{array}$ & $\begin{array}{l}\text { RFP, RBT, CAM, EB, } \\
\text { quinolones, } \\
\text { aminoglycosides }\end{array}$ & $\begin{array}{l}\text { RFP, RBT, CAM, } \\
\text { EB (intermediate) }\end{array}$ \\
\hline Treatment & CAM+INH 12 months & CAM+MFLX 6 months & $\begin{array}{c}\mathrm{CAM}+\mathrm{EB}+\mathrm{RBT}+\mathrm{INH} 4 \text { months } \\
\rightarrow \mathrm{CAM}+\mathrm{EB}+\mathrm{RBT} 2 \text { months }\end{array}$ \\
\hline Outcome & $\begin{array}{l}\text { died of other disease } \\
\text { (CMV infection, } \\
\text { bacteremia) }\end{array}$ & complete remission & complete remission \\
\hline
\end{tabular}

ministration of antimycobacterial agents, or the rapid immune restoration by cART.

We administered $\mathrm{RBT}+\mathrm{CAM}+\mathrm{EB}$, the standard regimen for disseminated MAC infection which can also be applied to many other NTM species (20). The regimen was intended to cover major Runyon II mycobacteria, i.e. M. xenopi, $M$. ulcerans, M. szulgai, and M. gordonae. In addition, because M. kansasii and other species requiring INH treatment were considered in the differential diagnosis, we added INH until those species could be ruled out. After 6 months of treatment, the infection had almost completely improved, though this isolate had a low susceptibility to the antimycobacterial agents. In comparison to the previous two cases, this strain showed lower minimal inhibitory concentration (MIC) to aminoglycosides and quinolones. Rifamycins, CAM and EB were relatively susceptible, though the MIC was higher than 
in the first case. Even so, the chemotherapy might have been effective, because usually no correlation has been shown between the susceptibility results and the clinical outcome for antimycobacterial agents (20). It is also possible to speculate that rapid immune restoration by cART may have led to the elimination of NTM.

The detection of mycobacterium in the sputum and abnormal elevation of serum ALP level (which is a common finding in cases with disseminated MAC infection of AIDS patients) were the only findings suggestive of NTM infection before the onset of IRS. While the other liver enzymes were close to normal levels, the ALP level peaked to 1,664 U/L on day 30, and then declined after treatment. As is often the case with AIDS patients, the patient was already on cART when mycobacterium was detected in the sputum after four weeks of culture. Although azythromycin was prescribed for prophylaxis, we could not prevent IRS caused by this NTM. To better predict the onset of a disseminated infection or IRS of NTM, an ALP elevation might be considered as an early marker and this had also been reported in the pertinent literature (21).

In conclusion, we experienced the case of an AIDS patient who developed $M$. shigaense lymphadenitis and skin lesion as IRS within 2 weeks after initiation of cART. He was treated with drainage and 6 months of antimycobacterial therapy. Owing to the rapid immune restoration by cART, the disease has been cured without any complications. Ours is the third case report of this novel mycobacterium, showing that this organism causes IRS in AIDS patients, just like other NTM does.

With the development of immunosuppressants and massive chemotherapies, the problems of opportunistic NTM infections are no longer limited to AIDS patients. We should keep in mind that a prompt diagnosis is needed for NTM infections in those compromised hosts. Further case reports of such rare species are needed to establish appropriate management strategies to treat such patients.

\section{Author's disclosure of potential Conflicts of Interest (COI).} Hiroshige Mikamo: Research funding, Toyama Kagaku Pharmaceutical, Pfizer. and Daiichi Sankyo.

\section{References}

1. Brown-Elliott BA, Wallace RJ Jr. 254. Infections caused by nontuberculous mycobacteria other than Mycobacterium avium complex. In: Mandell's Principle and practice of infectious diseases. 8th edition. Saunders, 2015: 2844-2852.

2. Horsburgh CR. Mycobacterium avium complex infection in the acquired immunodeficiency syndrome. N Engl J Med 324: 13321338, 1991.

3. Lawn SD, Bekker LG, Miller RF. Immune reconstitution disease associated with mycobacterial infections in HIV-infected individuals receiving antiretrovirals. Lancet Infect Dis 5: 361-373, 2005.

4. Raszka WV Jr, Skillman LP, McEvoy PL, Robb ML. Isolation of nontuberculous, non-avium mycobacteria from patients infected with human immunodeficiency virus. Clin Infect Dis 20: 73-76, 1995.
5. Telenti A, Marchesi F, Balz M, Bally F, Böttger EC, Bodmer T. Rapid identification of mycobacteria to the species level by polymerase chain reaction and restriction enzyme analysis. J Clin Microbiol 31: 175-178, 1993.

6. Roth A, Fischer M, Hamid ME, Michalke S, Ludwig W, Mauch H. Differentiation of phylogenetically related slowly growing mycobacteria based on 16S-23S rRNA gene internal transcribed spacer sequences. J Clin Microbiol 36: 139-147, 1998.

7. Kim BJ, Lee SH, Lyu MA, et al. Identification of mycobacterial species by comparative sequence analysis of the RNA polymerase gene (rpoB). J Clin Microbiol 37: 1714-1720, 1999.

8. Springer B, Wu WK, Bodmer $\mathrm{T}$, et al. Isolation and characterization of a unique group of slowly growing mycobacteria: description of Mycobacterium lentiflavum sp. nov. J Clin Microbiol 34: 1100-1107, 1996.

9. Cingolani A, Sanguinetti M, Antinori A, et al. Brief report: disseminated mycobacteriosis caused by drug-resistant Mycobacterium triplex in a human immunodeficiency virus-infected patient during highly active antiretroviral therapy. Clin Infect Dis 31: 177179, 2000.

10. Montejo M, Goicoetxea J, Agesta N, Gil A, Urra E, Jimenez MS. Cutaneous infection by Mycobacterium lentiflavum in a patient with HIV. Dermatology 213: 173-174, 2006.

11. Teruya H, Tateyama M, Hibiya K, et al. Pulmonary Mycobacterium parascrofulaceum infection as an immune reconstitution inflammatory syndrome in an AIDS patient. Intern Med 49: 18171821, 2010.

12. Nakanaga K, Hoshino Y, Wakabayashi M, et al. Mycobacterium shigaense sp. nov., a novel slowly growing scotochromogenic mycobacterium that produced nodules in an erythroderma patient with severe cellular immunodeficiency and a history of Hodgkin's disease. J Dermatol 39: 389-396, 2012.

13. Cui P, Vissa V, Li W, et al. Cutaneous Mycobacterium shigaense infection in immunocompetent woman, China. Emerg Infect Dis 19: 819-820, 2013.

14. Nightingale SD, Byrd LT, Southern PM, Jockusch JD, Cal SX, Wynne BA. Incidence of Mycobacterium avium-intracellulare complex bacteremia in human immunodeficiency virus-positive patients. J Infect Dis 165: 1082-1085, 1992.

15. Chaisson RE, Moore RD, Richman DD, Keruly J, Creagh T. Incidence and natural history of Mycobacterium avium-complex infections in patients with advanced human immunodeficiency virus disease treated with zidovudine. The Zidovudine Epidemiology Study Group. Am Rev Respir Dis 146: 285-289, 1992.

16. Phillips $P$, Bonner $S$, Gataric N, et al. Nontuberculous mycobacterial immune reconstitution syndrome in HIV-infected patients: spectrum of disease and long-term follow-up. Clin Infect Dis 41: 1483-1497, 2005.

17. Lawn SD, Checkley A, Wansbrough-Jones MH. Acute bilateral parotitis caused by Mycobacterium scrofulaceum: immune reconstitution disease in a patient with AIDS. Sex Transm Infect 81: 517$518,2005$.

18. French MA, Lenzo N, John M, et al. Immune restoration disease after the treatment of immunodeficient HIV-infected patients with highly active antiretroviral therapy. HIV Med 1: 107-115, 2000.

19. Robertson J, Meier M, Wall J, Ying J, Fichtenbaum CJ. Immune reconstitution syndrome in HIV: validating a case definition and identifying clinical predictors in persons initiating antiretroviral therapy. Clin Infect Dis 42: 1639-1646, 2006.

20. Griffith DE, Aksamit T, Brown-Elliott BA, et al. An official ATS/ IDSA statement: diagnosis, treatment, and prevention of nontuberculous mycobacterial diseases. Am J Respir Crit Care Med 175: 367-416, 2007.

21. Hsieh SM, Hung CC, Chen MY, Hsueh PR, Chang SC, Luh KT. Clinical features and outcome in disseminated mycobacterial diseases in AIDS patients in Taiwan. AIDS 12: 1301-1307, 1998. 
Intern Med 55: 3375-3381, 2016 DOI: 10.2169/internalmedicine.55.6996

The Internal Medicine is an Open Access article distributed under the Creative Commons Attribution-NonCommercial-NoDerivatives 4.0 International License. To view the details of this license, please visit (https://creativecommons.org/licenses/ by-nc-nd/4.0/).

(C) 2016 The Japanese Society of Internal Medicine http://www.naika.or.jp/imonline/index.html 